Archived version from NCDOCKS Institutional Repository http://libres.uncg.edu/ir/asu/

\title{
Appalachỉan
}

B O O N E, N O R T H C A R O L I N A

\section{Trading While Sleepy? Circadian Mismatch And Mispricing In A Global Experimental Asset Market}

\author{
By: David L. Dickinson, Ananish Chaudhuri, \& Ryan Greenaway-McGrevy
}

\begin{abstract}
Traders in global markets operate at different local times-of-day. This implies heterogeneity in circadian timing and likely sleepiness or alertness of those traders operating at less or more optimal times of the day, respectively. This, in turn, may lead to differences in both individual-level trader behavior as well as market level outcomes. We examined these factors by administering single-location and global sessions of an online asset market experiment that regularly produces mispricing and valuation bubbles. Global sessions involved real time trades between subjects in New Zealand and the U.S (i.e., "global" markets) with varied local times of day for each location. Individual traders at suboptimal times of day (or, "circadian mismatched" traders) engaged in riskier trading strategies, such as holding shares (the riskier asset) in later trading rounds and mispricing shares to a greater degree. These strategies resulted in lower earnings for circadian mismatched traders, especially in heterogeneous markets that also included traders at more optimal times-of-day. These differences were also reflected in market level outcomes. Markets with higher circadian mismatch heterogeneity across traders were more likely to exhibit longer lasting asset bubbles and greater share turnover volume. Overall, our results draw attention to a unique, but underappreciated, factor present across traders in global market environments, namely, differences in sleepiness across traders. Thus, this study hopes to highlight the role of circadian mismatch in attempting to understand trader behavior and, ultimately, market volatility.
\end{abstract}

Dickinson, D.L., Chaudhuri, A. \& Greenaway-McGrevy, R. Trading while sleepy? Circadian mismatch and mispricing in a global experimental asset market. Exp Econ 23, 526-553 (2020). Publisher version of record available at: https://doi.org/10.1007/s10683-019-09623-0 


\title{
Trading while sleepy? Circadian mismatch and mispricing in a global experimental asset market
}

\author{
David L. Dickinson $^{1,4,5} \cdot$ Ananish Chaudhuri ${ }^{2,3} \cdot$ Ryan Greenaway-McGrevy $^{2}$
}

Received: 26 November 2018 / Revised: 8 August 2019 / Accepted: 16 August 2019 /

Published online: 30 August 2019

(c) Economic Science Association 2019

\begin{abstract}
Traders in global markets operate at different local times-of-day. This implies het-erogeneity in circadian timing and likely sleepiness or alertness of those traders operating at less or more optimal times of the day, respectively. This, in turn, may lead to differences in both individual-level trader behavior as well as market level outcomes. We examined these factors by administering singlelocation and global sessions of an online asset market experiment that regularly produces mispricing and valuation bubbles. Global sessions involved real time trades between subjects in New Zealand and the U.S (i.e., "global" markets) with varied local times of day for each location. Individual traders at suboptimal times of day (or, "circadian mis-matched" traders) engaged in riskier trading strategies, such as holding shares (the riskier asset) in later trading rounds and mispricing shares to a greater degree. These strategies resulted in lower earnings for circadian mismatched traders, especially in heterogeneous markets that also included traders at more optimal times-of-day. These differences were also reflected in market level outcomes. Markets with higher circadian mismatch heterogeneity across traders were more likely to exhibit longer lasting asset bubbles and greater share turnover volume. Overall, our results draw attention to a unique, but underappreciated, factor present across traders in global market environments, namely, differences in sleepiness across traders. Thus, this study hopes to highlight the role of circadian mismatch in attempting to understand trader behavior and, ultimately, market volatility.
\end{abstract}

Keywords Asset markets · Experiments · Bubbles $\cdot$ Sleep $\cdot$ Circadian rhythm

JEL Classification C92 · G12 · G15 · D84

Electronic supplementary material The online version of this article (https://doi.org/10.1007/s1068 3-019-09623-0) contains supplementary material, which is available to authorized users.

David L. Dickinson

dickinsondl@appstate.edu

Extended author information available on the last page of the article 


\section{Introduction}

Globalization, along with its impact on diverse aspects of our lives, has also led to the creation of global financial markets (e.g., markets for foreign exchange, treasuries, commodities and crypto-currencies). Such markets involve traders who are geographically dispersed in real time. It is now common-place for a trader in Tokyo to engage in markets located in, London, New York or elsewhere. This raises an underappreciated issue with implications regarding asset pricing in such global markets, and this issue will likely become more prominent with increasing globalization and improving technology. Specifically, the presence of globally dispersed traders implies heterogeneity in the local time-of-day for those traders and, consequently, increased circadian-driven sleepiness/alertness heterogeneity across these market participants.

The issue of how trader heterogeneity may impact market-level outcomes or asset mispricing is an important one that has received considerable attention in the literature (De Long et al. 1990; Griffin et al. 2011; Baghestanian et al. 2015; Akiyama et al. 2017; Hanaki et al. 2017). ${ }^{1}$ Related to our topic is previous research that has identified "circadian desynchronosis" as a cause of the negative effect of daylight savings time (DST) changes on stock returns (Kamstra et al. 2000). However, our research question is different in that we examine how differences in circadian sleep/ wake rhythm across asset market traders affects asset mispricing. Because of the heterogeneity in the circadian timing of decisions among participants in real-time global markets, those trading at more suboptimal local times of day (e.g., traders operating at 4:00 am), who can be thought of as those with significant "circadian mismatch", may be at particular disadvantage when high level thinking and anticipation become crucial. Therefore, we hypothesize that global markets generate a natural heterogeneity in critical cognitive resource availability that may impact trader behavior and market outcomes in important ways.

Observational data presents numerous challenges in any attempt to establish causal relationships when considering a question like this: how does heterogeneity in circadian patterns affect individual and market level outcomes? There is some evidence that dual-listed financial securities exhibit more volatility on global markets compared to domestic markets that are closed to foreign traders. For example, Chinese American Depository Receipts (ADRs) exhibit higher volatility than their domestically-listed counterparts (Chen et al. 2010; He and Yang 2012; Wu and Chen 2015; Liu 2017). ${ }^{2}$ While securities listed on the NYSE can be purchased by domestic and foreign traders operating at different local times, Chinese stock exchanges are only open to local traders operating within the same

\footnotetext{
1 A recent paper by Hanaki et al. (2017) finds a significant increase in asset mispricing in experimental asset markets with both high and low cognitive ability subjects, which may also implicate temporary variations in available cognitive resources as a source of asset mispricing and market bubbles.

2 An American depositary (or depository) receipt (ADR) represents securities of a foreign company that trade in U.S. financial markets. These are denominated and pay dividends in U.S. dollars and may be traded like regular shares of stock. They are traded during U.S. trading hours.
} 
time zone. A reasonable conjecture is that excess volatility in ADR trading is the result of globally located ADR trader activity-some of these traders are operating at more sub-optimal times of day relative to other traders in the market.

With this field data example, the asset underlying the US-listed ADR and the domestically-listed share is the same and, because the renminbi/USD exchange rate is fixed, we believe that this as close as we can get to a natural experiment with observational data.

These results suggest that market level outcomes may differ when there is greater heterogeneity in the circadian state of traders, and this is the theme we wish to explore in a more controlled setting. Another example is provided by Gao et al. (2018), who identify statistically and economically significant differences in intraday patterns for returns on exchange-traded funds; returns in the final $30 \mathrm{~min}$ of the day matched returns in the first $30 \mathrm{~min}$. The authors suggest that this effect is driven primarily by late informed (or slow to process information) buyers who take several hours to process new information. Adverse sleep states have been shown to compromise the processing of new information (e.g., Dickinson and Drummond 2008; Dickinson et al. 2016), and so a given percentage of sleepy traders in a market may generate such a data pattern as in Gao et al. (2018). Unfortunately, data from these naturally occurring market examples pose complications in cleanly identifying any singular mechanism. Therefore, generating primary data in a controlled laboratory environment is a way to minimize potential confounding factors. We therefore consider this research an important first step in our attempt to understand the importance of circadian heterogeneity, and likely heterogeneity in sleepiness in general, in real-time global markets.

We study a commonly used (and well-validated) experimental asset market environment to examine asset pricing and trader decisions. Research on how circadian timing affects behavior in strategic environments, in general, is particularly lacking. Our results show that the circadian suboptimal state of a trader predicts riskier trading strategies (i.e., holding shares, the riskier asset, longer and mispricing the shares more) and reduced earnings. Further, we show that these phenomena of riskier trading strategies and lower earnings of circadian mismatched traders are particularly exacerbated in markets that have a greater degree of circadian mismatch heterogeneity. In other words, it is not enough for all traders in a market to be operating at sub-optimal times of day (say, 4:00 am). What is crucial is the presence of both circadian matched (those at more optimal timesof-day) and circadian mismatched traders, which allows the former to exploit the "mistakes" of the latter. Finally, we demonstrate that the heterogeneity in this circadian state across traders in a market may manifest itself in aggregate market level outcomes such as bubble duration and asset turnover volume. A key insight of our study is that global markets (that bring together traders operating at different local times of the day) are far more likely to generate the type of circadian mismatch heterogeneity that is crucial for greater mispricing and lower earnings for traders operating at sub-optimal times of day. To our knowledge, this paper is the first to systematically examine the impact of this feature of globalization (i.e., heterogeneity in circadian mismatch) on trader behavior and asset market outcomes. 


\section{Background}

In general, unimpaired cognition would seem necessary for successful asset market performance. This would implicate one's ability to engage prefrontal brain regions that are important in high-level executive function. Deliberative thinking processes may also be important for limiting the influence of cognitive biases in such decision environments, such as trader overconfidence. Evidence shows that those scoring higher at Theory of Mind (ToM) skills exhibit increased medial Prefrontal Cortex activation (mPFC) and are better at predicting prices in asset markets with insiders (Bruguier et al. 2010). Relatedly, researchers have found that mentalizing during strategic interactions (Hampton et al. 2008) invokes regions of the brain known to be impacted by sleep deprivation (Yoo et al. 2007). Though brain regions implicated in ToM appear to be distinct from those involved in mathematical calculations, the fact remains that successful anticipation of future market outcomes involves higher levels of cognitive reasoning implicated in ToM (Coricelli and Nagel 2009). Others have reported that both analytical and mentalizing dimensions of cognition are required for successful trading behavior (Hefti et al. 2016; Corgnet et al. 2018). ${ }^{3}$

A different strand of research has examined the importance of behavioral biases, such as overconfidence, on trader performance. For example, Michailova and Schmidt (2016) found that overconfidence led to larger price bubbles and such overconfidence was larger in the latter half of the 15-round asset market (see also Kirchler and Maciejovsky 2002). Scheinkman and Xiong (2003) offered a theoretical argument based on the idea that traders may be willing to pay more than their expectation of an asset's future dividend value as long as one believes another trader will subsequently be willing to pay even more. ${ }^{4}$

The connections between mentalizing (ToM), overconfidence, and asset market behavior are important given the results in the sleep literature. Specifically, neuroimaging studies have shown that sleep loss disproportionately impacts prefrontal and executive function brain regions (Horne 1993; Muzur et al. 2002; Chee and Chuah 2008), and behavioral research has shown that anticipation of other's choices can be harmed even at relatively mild levels of circadian mismatch (Dickinson and McElroy 2012). Furthermore, sleep researchers have found a recent neural basis for claiming that mild sleep restriction may increase optimism by accentuating the brain's focus on positive reward anticipation (Venkatraman et al. 2011). ${ }^{5}$ In a recent

\footnotetext{
3 A recent paper by Corgnet et al. (2018) also concludes that standard cognitive skills are not necessarily what make traders successful, but rather display of behavioral biases such as overconfidence may be a stronger indicator of poor performance in asset markets. However, they also conclude that ToM skills have only a marginal effect, which is different than what others have concluded (e.g., Bruguier et al. 2010).

4 Others have found that overconfidence in equity trading data may result in higher frequency trading activity (Grinblatt and Keloharju 2009).

5 More specifically, to the extent that sleep deprivation may selectively increase activation in portions of the prefrontal cortex (i.e., the ventro-medial PFC), the evidence suggests that such increased activation represents the decision maker's increased focus on potential monetary gains. In other words, in the context of our task where monetary gains and losses are at stake, the increased PFC activation that may result from sleepy traders would suggest an increased optimism bias as opposed to an increase in decision quality (see Venkatraman et al. 2007, 2009, 2011).
} 
paper, Castillo et al. (2017) also found a direct link between suboptimal circadian timing and riskier asset bundle choices in an individual decision-making environment. This finding adds "increased preference for risk" to the potential mechanisms that may be engaged in "sleepier" traders. Taken together, prior findings suggest that sleepiness, in a general sense, is linked to a reduced capacity to anticipate, an increased preference for risk, and the increased potential for optimism in relevant decision environments. ${ }^{6}$ This has the potential to increase asset mispricing, especially if there is significant circadian heterogeneity in the market such that "alert" traders are able to exploit the reduced anticipation (or increased overconfidence or risk taking) of "sleepy"("tired") traders. Our premise is that such heterogeneity is likely to be higher in global markets.

\section{Hypotheses}

The research summarized above supports a set of hypotheses regarding market outcomes and individual behavior in markets with greater heterogeneity in circadian mismatch across traders. Specifically, heterogeneity in mentalizing skills (i.e., one's ability to anticipate), overconfidence, and risk attitude will be higher in markets with greater heterogeneity in circadian mismatch if, as we assume, suboptimal times-ofday impact these behavioral tendencies. As noted above, we expect this to be more likely in our global market sessions (henceforth, "global markets"), but we will base our hypotheses on a more precise measure of market-level heterogeneity as indicated in the Experimental Design section below. ${ }^{7}$ Sleepy traders, in the presence of more alert traders, may fuel valuation bubbles: they fail to anticipate overvaluation (or a market "crash") and continue mispricing the asset; they are overly optimistic regarding price trends during bubbles, and/or they display an increased preference for the risk inherent in holding asset shares with uncertain value. The presence of less-sleepy traders (i.e., lesser degree of circadian mismatch) in those same markets provides the opposing tendencies to fuel bilateral trades. This leads to our first hypothesis, which focuses on aggregate market level outcomes.

\footnotetext{
${ }^{6}$ Altered mood states may also be a factor to consider, as previous authors have hypothesized that mood may explain morning sunshine impacts on stock market returns, which may otherwise be difficult to reconcile with a rational expectations model (Hirshleifer and Shumway 2003). Yet another study in experimental asset markets suggests irrationality of traders may fuel speculative bubbles (Lei et al. 2001), though we appeal to a recent asset bundle choice experiment that found mild circadian mismatch may impact preferred asset bundles with no measurable change in rationality of choice (see Castillo et al. 2017).

7 Some studies such as Toplak et al. (2011), which rely on the Frederick (2005) Cognitive Reflection Task (CRT), suggest that behavioral differences are driven primarily by differences in cognitive skills. Therefore, we include a control for math abilities in our analysis. While we do not measure CRT in the present study, a related study (Castillo et al, 2017) measures CRT in an individual decision asset bundle choice task under conditions of circadian match and mismatch and found no significant difference in CRT scores across these randomly assigned treatment groups.
} 
Hypothesis 1 Markets with greater circadian mismatch heterogeneity will produce more significant asset price bubbles.

Our second hypothesis focuses on individual trader behavior. A premise of our hypotheses is the fact that we predict circadian mismatch increases preference for riskier asset bundles (i.e., more shares over cash), increases overconfidence, and reduces a trader's ability to anticipate others' actions (e.g., hold shares while others are selling). Recent results in Castillo et al. (2017) support this hypothesis over the alternative (and perhaps common) intuition that sleepy decision makers are more irrational. While increased irrationality may be true at more acute levels of sleepiness, such as those generated by total sleep deprivation or chronic and severe sleep restriction, the circadian mismatch generated sleepiness we induce is more in line with the Castillo et al. (2017) approach.

Relatedly, extant research highlights the potential for increased optimism regarding favorable monetary outcomes. So, traders at suboptimal times of day may continue to optimistically overprice the asset and choose to hold more assets in anticipation of favorable dividend draws or resale prices. Or, they may simply be less able to anticipate the bubble burst in a state of greater circadian mismatch. It is common knowledge that shares are redeemed at fundamental value at the end of the last market trading round and so all bubbles eventually crash, at least in terms of final redemption prices. Assuming one's expected ability to resell shares at a profit should decrease in the number of remaining trading rounds, holding shares in late trading rounds would be a riskier strategy for traders even in the flat fundamental share value setting we use. We summarize this conjecture, that circadian mismatched traders will employer riskier trading strategies, in our second hypothesis.

Hypothesis 2 Circadian mismatched traders will employ riskier trading strategies: (1) they will hold more shares particularly in later trading rounds (a riskier strategy); and (2) they will misprice shares to a greater degree than more circadian matched traders.

Finally, we explore earnings differences across trader types. Reduced mentalizing or increased overconfidence among circadian mismatched traders should imply poorer decisions that may be exploited by more circadian matched traders and result in lower earnings. Increased risk taking, per se, may or may not impact average trader earnings, and so differences in earnings in our design may reflect more the impact that circadian timing has on anticipation or overconfidence (i.e., inaccurate beliefs). Though we do not collect direct evidence on beliefs, lower earnings of sleepy traders would be indirect evidence that circadian suboptimal timing impacts the quality of trader decisions that typically depend on the accuracy of one's beliefs. We highlight the predicted effect on earnings as our third hypothesis:

Hypothesis 3 Circadian mismatched traders will earn less. This effect will be largest in markets with higher circadian heterogeneity. 


\section{Experimental design}

The limit-order asset market environment we implement is based on the constant (flat) fundamental asset value design of Bostian et al. (2005) and Bostian and Holt (2009). Groups of 7-13 subjects (median group size $=11$ subjects) participated in the online asset market experiment. Participants $(n=303)$ from both New Zealand and the U.S. were recruited for this study. Recruitment was from University populations in both locations, and there were no exclusion criteria other than the restriction that participants be at least 18 years of age. Participants were not asked to come into a physical lab and could participate from any web-access location of their choice. Subjects were recruited for 2 -h sessions that required them to be online at specific local time-of-day on the day of the session, and they were paid a fixed payment that varied depending on the local time of day of the session (see note to Table 1). ${ }^{8}$ Sessions were scheduled so that all subjects participated on either a Tuesday, Wednesday, Thursday (no matter which location) to avoid weekend sleep effects as much as possible. We anticipated that those participating during nighttime hours would likely participate from their homes, which also constituted a risk management feature of the design (i.e., no sleepy travel required, and participants could sleep immediately after participation, if desired).

Subjects were instructed that, at the session start time, the experimenter would email a link to a short (5 min) online survey to collect demographic and self-report sleep data, as well as a validated measure of "morningness" or "eveningness" preferences (Adan and Almirall 1991). Self-reported sleepiness was elicited in the survey to validate our methodology. The experimenter monitored survey responses in real time to verify total logins, and this determined the final group size used to then configure the online asset market experiment. ${ }^{9}$

Experiments were conducted through Veconlab's limit-order asset market experiment option ${ }^{10}$ and the subjects were told that they would be emailed the login credentials for the main market experiment shortly after completion of the initial online survey. The market is a call auction mechanism where traders may choose to submit orders to buy and/or sell shares in a series of trading rounds. Traders were also allowed to submit an order to buy or sell zero shares, which the experimenter asked they do rather than do nothing so that the experimenter was more assured that the online traders had not abandoned the experiment. Within the asset market experiment, the experimenter utilized a message board embedded in the program to post messages to subjects individually or as a group (e.g., "30 s until the round ends, please make your final decisions for this round"). The experimenter also continued to monitor email in the event a subject sent a clarification question because the

\footnotetext{
${ }^{8}$ Rates of subjects who signed up but were not online for the experiment (i.e., virtual no-shows) were as follows: 4 am-20\%; 8 am-12.5\%; noon-15.6\%; 4 pm-20\%; 8 pm-11\%; midnight-24\%.

9 The experimenter conducted the experiments online and was in the same time zone as the east coast US subjects.

10 The various experiment options for the Veconlab Internet-based platform for experiments can be accessed at http://veconlab.econ.virginia.edu/admin.htm. The specific experiment used is the "Limit Order Market" option under the "Asset Market" submenu of the "Finance/Macro" experiment section.
} 
Table 1 Experiment locations, local times, and number of participants

\begin{tabular}{|c|c|c|c|c|c|}
\hline $\begin{array}{l}\text { Market } \\
\text { session \# }\end{array}$ & $\begin{array}{l}\text { Global } \\
\text { or local }\end{array}$ & $\begin{array}{l}\text { Session details } \\
\text { Total number of subjects } \\
\text { Place- } 24 \text { h time [\#obs at relevant } \\
\text { location(s)] }\end{array}$ & $\begin{array}{l}\text { Circadian GINI } \\
\frac{\sum_{i=1}^{n} \sum_{j=1}^{n}\left|x_{i}-x_{j}\right|}{2 n \sum_{i=1}^{n} x_{i}}\end{array}$ & $\begin{array}{l}\text { Circadian } \\
\text { mismatch, } x_{i}, \\
\text { heterogeneity } \\
\text { measure } \\
\frac{2 \sum_{i=1}^{n} \sum_{j=1}^{n}\left|x_{i}-x_{j}\right|}{n(n-1)}\end{array}$ & $\begin{array}{l}\text { Overall } \\
\text { level of } \\
\text { circadian } \\
\text { mismatch } \\
\frac{4 \sum_{i=1}^{n} x_{i}}{n-1}\end{array}$ \\
\hline 1 & Local & $9 ; \mathrm{NZ}-12: 00(\mathrm{n}=9)$ & 0.114 & 0.122 & 1.070 \\
\hline 2 & Global & $11 ;$ NZ-24:00 $(n=5) \&$ US-8:00 $(n=6)$ & 0.124 & 0.300 & 2.424 \\
\hline 3 & Global & $11 ;$ NZ-4:00 $(n=6) \&$ US-12:00 $(n=5)$ & 0.143 & 0.341 & 2.377 \\
\hline 4 & Global & $9 ;$ NZ-8:00 $(n=4) \&$ US-16:00 $(n=5)$ & 0.198 & 0.334 & 1.690 \\
\hline 5 & Global & $12 ;$ NZ-20:00 $(n=7) \&$ US-4:00 $(n=5)$ & 0.249 & 0.388 & 1.556 \\
\hline 6 & Global & $11 ; N Z-12: 00(n=5) \&$ US-20:00 $(n=6)$ & 0.198 & 0.119 & 0.600 \\
\hline 7 & Global & $9 ;$ NZ-16:00 $(n=5) \&$ US-24:00 $(n=4)$ & 0.096 & 0.076 & 0.785 \\
\hline 8 & Local & $10 ; N Z-12: 00(n=10)$ & 0.115 & 0.126 & 1.102 \\
\hline 9 & Global & $11 ;$ NZ-24:00 $(n=5) \&$ US-8:00 $(n=6)$ & 0.180 & 0.401 & 2.224 \\
\hline 10 & Global & $11, N Z-4: 00(n=6) \&$ US-12:00 $(n=5)$ & 0.145 & 0.325 & 2.248 \\
\hline 11 & Global & $10 ;$ NZ-8:00 $(n=4) \&$ US-16:00 $(n=6)$ & 0.187 & 0.232 & 1.238 \\
\hline 12 & Global & $12 ;$ NZ-20:00 $(n=7) \&$ US-4:00 $(n=5)$ & 0.234 & 0.377 & 1.611 \\
\hline 13 & Global & $10 ; N Z-12: 00(n=5) \&$ US-20:00 $(n=5)$ & 0.181 & 0.094 & 0.520 \\
\hline 14 & Global & $10 ;$ NZ-16:00 $(n=6) \&$ US-24:00 $(n=4)$ & 0.125 & 0.105 & 0.838 \\
\hline 15 & Local & 13 ; US-12:00 $(n=13)$ & 0.113 & 0.102 & 0.900 \\
\hline 16 & Local & $12 ;$ US-12:00 $(n=12)$ & 0.123 & 0.168 & 1.371 \\
\hline 17 & Local & 7; US-4:00 (n=7) & 0.013 & 0.047 & 3.601 \\
\hline 18 & Local & $8 ;$ US-20:00 $(n=8)$ & 0.152 & 0.066 & 0.433 \\
\hline 19 & Local & $10 ;$ US-4:00 $(n=10)$ & 0.013 & 0.043 & 3.418 \\
\hline 20 & Local & $11 ;$ US-20:00 $(n=11)$ & 0.096 & 0.032 & 0.336 \\
\hline 21 & Local & 11; US-20:00 $(\mathrm{n}=11)$ & 0.103 & 0.034 & 0.328 \\
\hline 22 & Local & $12 ; \mathrm{US}-20: 00(\mathrm{n}=12)$ & 0.035 & 0.010 & 0.276 \\
\hline 23 & Local & 8; US-4:00 (n=8) & 0.013 & 0.043 & 3.383 \\
\hline 24 & Local & $10 ;$ US-20:00 $(n=10)$ & 0.138 & 0.055 & 0.399 \\
\hline 25 & Local & $11 ;$ US-4:00 $(n=11)$ & 0.015 & 0.049 & 3.329 \\
\hline 26 & Local & $10 ;$ US-4:00 $(n=10)$ & 0.014 & 0.049 & 3.383 \\
\hline 27 & Local & $9 ; \mathrm{NZ}-20: 00(\mathrm{n}=9)$ & 0.026 & 0.008 & 0.295 \\
\hline 28 & Local & $12 ; \mathrm{NZ}-20: 00(\mathrm{n}=12)$ & 0.144 & 0.061 & 0.424 \\
\hline 29 & Local & $13 ;$ NZ-20:00 $(n=13)$ & 0.131 & 0.047 & 0.356 \\
\hline \multicolumn{3}{|c|}{ Global vs Local Mann-Whitney statistic ( $p$ value) } & $\begin{array}{l}-3.612 \\
(p<.01)\end{array}$ & $\begin{array}{l}-3.898 \\
(p<.01)\end{array}$ & $\begin{array}{l}-1.107 \\
(p<.27)\end{array}$ \\
\hline
\end{tabular}

Fixed payments for participation was $\$ 10$ for sessions at local times of noon or 4:00 pm; $\$ 20$ for sessions at local times of 8:00 am, 8:00 pm, or midnight; $\$ 30$ for sessions at local times of 4:00 am. Additional earnings were based on outcomes in the asset market

Bold values indicate significance at the $5 \%$ or better level for the Mann-Whitney test

message feature in the asset market experiment was unidirectional (experimenter to subject(s) only). Questions to the experimenter were, however, minimal given the Veconlab instructional pages included comprehension examples of how transactions were determined, and earnings calculated prior to allowing the subject to enter 
the first market decision round (see online supplementary materials for experiment instructions).

In the experimental asset market, subjects were endowed with $\$ 50$ of experimental cash and 6 shares of the experimental asset. Two treatments varied the asset returns in a way that preserved a constant fundamental asset value of $\$ 7$ in all round of all treatments. Specifically, in the Low Returns treatment, cash held at the end of each round received $10 \%$ interest, and in each round, shares earned a dividend of either $\$ 0.40$ or $\$ 1.00$ (so, the expected dividend was $\$ .70$ per round in Low Returns) and shares were redeemed for $\$ 7.00$ at the end of the final period of the treatment. As such, the fundamental share value is found by the simplified perpetuity formula $\$ .70 / .10=\$ 7.00$ (see Holt et al. 2017 for the justification of a flat fundamental value design for the asset market). ${ }^{11}$ In the High Returns treatment, cash paid $20 \%$ interest but the dividend draw on shares in each round was either $\$ 1.10$ or $\$ 1.70$, which resulted in an expected dividend draw of $\$ 1.40$ in each round. Consequently, High Returns infused more cash into the market, which has been shown to amplify bubble formation (Holt et al. 2017), but the fundamental share value was still $\$ 1.40 / .20=\$ 7.00$ per share in each round.

A session lasted for 30 rounds, with 15 rounds in each treatment, High or Low Returns. The order was counter-balanced across sessions. Experimental earnings were paid at a rate of $\$ 100$ experimental dollars $=$ US $\$ 1$. Subject payments were arranged within $24 \mathrm{~h}$ of the session completion. In New Zealand, subjects were given the opportunity to receive their cash payment (in equivalent NZ dollars corresponding to US earnings ${ }^{12}$ ) as soon as the day after the experiment. The U.S. subjects were paid their earnings through PayPal within $24 \mathrm{~h}$ of the end of the session. Average asset market earnings for all participants were US $\$ 18.09 \pm 8.55$ (median \$18.11). For the distinct treatments, earnings were US \$3.81 \pm 1.74 (median \$3.60) for Low Returns and US $\$ 14.81 \pm 7.24$ (median $\$ 14.54$ ) for High Returns. In addition, participants received a guaranteed fixed participation compensation of US $\$ 10, \$ 20$, or $\$ 30$ depending on whether the local time of day of the experiment session was noon or 4:00 pm (\$10), 8:00 am or 8:00 pm (\$20) or 4:00 am (\$30) (see Note to Table 1).

Seventeen of our sessions involved traders in a single geographic location (East Coast, USA, or Auckland, New Zealand), while the other 12 sessions involved markets populated with traders from both of those locations, which were 16 time zones apart at the time of the experiment sessions (see Table 1 for details regarding the

\footnotetext{
11 One of the sessions (Market 25, Appalachian State, 4:00 am) inadvertently used a dividend draw in the Low Returns treatment that allowed for a 1/10 chance of a zero dividend in just round 1 of the treatment-dividends were explained to participants as based on the roll of a 10-sided die. Rather than rolls 1-5 producing a $\$ .40$ dividend and rolls $6-10$ producing a $\$ 1.00$ dividend, the table showing the dividend for each possible die outcome in round 1 listed a $\$ 0.00$ dividend if the die roll was a 1 . The realized dividend in that round was, in fact, the $\$ 1.00$ high dividend, but this implies fundamental share value in the first round of that treatment for that one market was closer to $\$ 6.70$ for round 1 and mechanically rising to $\$ 6.96$ in round 10 . The subjects correctly saw the intended dividend outcomes that would result from the die outcome as $\$ .40$ for rolls $1-5$ and $\$ 1.00$ for rolls $6-10$ in rounds $2-10$ and there is no evidence this error, which was never realized in the dividend draw, affected behavior in any way.

12 At the times the experiments were carried out the exchange rate was between US $\$ 1=\mathrm{NZ} \$ 1.38$ $\$ 1.47$.
} 
session timing and locations). We label single-location markets as "local markets" while real-time trading with participants in both locations are what we call "global markets". Notably, traders were not aware of other traders' location and therefore had no idea that others might be in a different country (market interactions were all online) and/or have different alertness levels. Sessions took place at local times of 12:00 noon, 4:00 pm, 8:00 pm, 12:00 midnight, 4:00 am, and 8:00 am at each location (see Table 1 for full details on market sessions that includes location and number of subjects per location at the various local times-of-day). As noted above, decisions were incentivized with payoffs that were a function of experimental earnings.

It is important that there is heterogeneity in the optimality of the local session time-of-day across subjects. Recall, the pre-experiment survey administers a validated short-form morningness-eveningness questionnaire. Evening-type subjects will generally possess a phase delay of roughly two hours relative to morning-type subjects in terms of their optimal alertness time-of-day. Smith et al. (2002) highlight the diurnal pattern of self-reported alertness ratings for individuals of different diurnal preferences types. We adapt their methodology in Fig. 1 with a normalized scale describing the level of sub-optimality of the local time of day, which we call mismatch level, or "MMlevel" $\in[0,1]$. The colored bands indicate clusters of high (red), medium (yellow), and low (green) predicted mismatch (MM) levels. We then construct a dichotomous variable HighMM $=1$ for those with MMLevel $\geq 0.50$. A s one can see from Fig. 1, this classifies as HighMM=1 those subjects that fall within the high cluster (red band) of objective circadian mismatch levels in Fig. 1. Thus, this dichotomous variable captures the more significant difference between the objective circadian suboptimal timing of those within the red band (e.g., anyone at 4:00 am, evening-types at 8:00 am, morning-types at midnight) compared to others. ${ }^{13}$ Our efforts in scoring such a variable using a validated diurnal preference measure and research-based alertness patterns reflects the focus of our study on the importance of objective time-of-day heterogeneity in our global markets. ${ }^{14}$

An additional way to capture the circadian heterogeneity in each asset market group is to calculate a GINI coefficient that describes the inequality in circadian mismatch levels across the traders in that market. To do this, we define the Gini coefficient for a given market as:

$$
G I N I=\frac{\sum_{i=1}^{n} \sum_{j=1}^{n}\left|x_{i}-x_{j}\right|}{2 n \sum_{i=1}^{n} x_{i}}
$$

\footnotetext{
13 The validity of this methodology is documented in Sect. 5 of this paper. There may be an additional concern regarding selection of subjects into the different time slots of the experiment. While we do not have all measures that might be desired on which to assess sample selection, we formally tested for differences in observable characteristics of our participants across the HighMM=0 and HighMM=1 participants. We found no significant differences in gender, age, race, math level, Epworth sleepiness, anxiety risk, depression risk, or self-reported recent sleep deprivation across these two samples of participants ( $p>.10$ in all instances: Mann-Whitney tests of medians).

14 In order to make sure that our results are not an artefact of this dichotomous classification of subjects into alert or sleepy categories, we also undertake a parallel analysis with the underlying continuous variable MMLevel (bounded by zero and one) as the regressor of interest. We say more on this issue below in Footnote 18, when we present our results.
} 


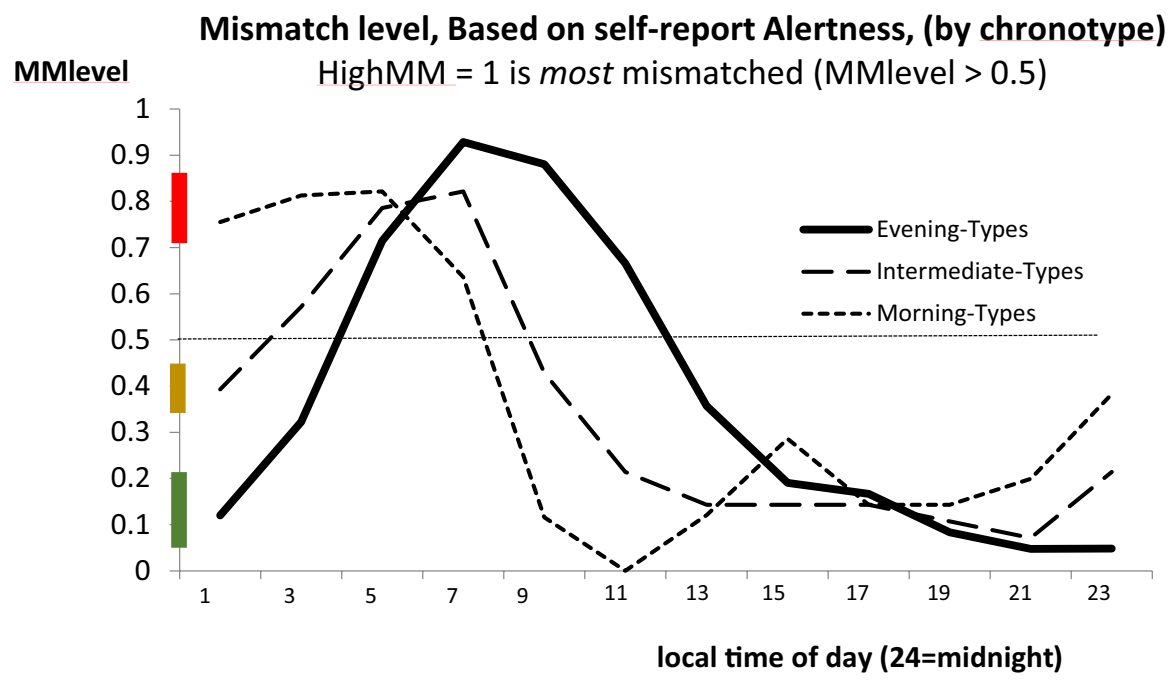

Fig. 1 Guide for scoring of High Mismatch variable (colored bands represent the clusters of scored MMlevel in our data). (Color figure online)

Note: Graph adapted from alertness levels in Fig. 1 in Smith et al. (2002)

where there are $n$ traders in the market, and $x_{\mathrm{i}}$ describes the circadian mismatch level of trader $i$ in the market. This definition describes the GINI coefficient as half the relative mean absolute difference between all pairwise circadian mismatch values in the market, with circadian mismatch defined as in Fig. 1. Table 1 includes the circadian GINI coefficient of each market session, along with normalized measures that represent the distinct numerator and denominator terms of the GINI coefficient in (1). The numerator focuses on the circadian heterogeneity across traders in each market, while the denominator term describes the overall level of circadian mismatch in the market. As can be seen at the bottom of Table 1, our global markets have a significantly higher circadian GINI coefficient compared to local markets, and the difference stems from circadian heterogeneity across traders and not from the mismatch levels across markets. While global markets have greater circadian heterogeneity, on average, notice in Table 1 that some local markets have greater circadian heterogeneity than some global markets; this is possible due to the mixture of morning-types, intermediate-types, and evening-types who are differentially mismatched at certain times-of-day. As such, when using a measure of market heterogeneity in our analysis, we will focus on the more descriptive market GINI coefficient rather than the dichotomous global versus local identifier of a market.

\section{Results}

Result 1 Circadian heterogeneity predicts bubble duration and share turnover, but this is limited to the High Returns treatment. 
The first of our three hypotheses, noted above, argues that markets with greater circadian mismatch heterogeneity will produce more significant asset price bubbles. In this section we look for evidence providing corroboration, or lack thereof, of this hypothesis. Figure 2 shows market trading prices across the 15 rounds of the Low Returns treatment. Panel A shows prices for local markets while Panel B does so for global markets. Figure 3 presents the corresponding information for local (Panel A) and global markets (Panel B) for the High Returns treatment. The thick black line

\section{Panel A: local markets}
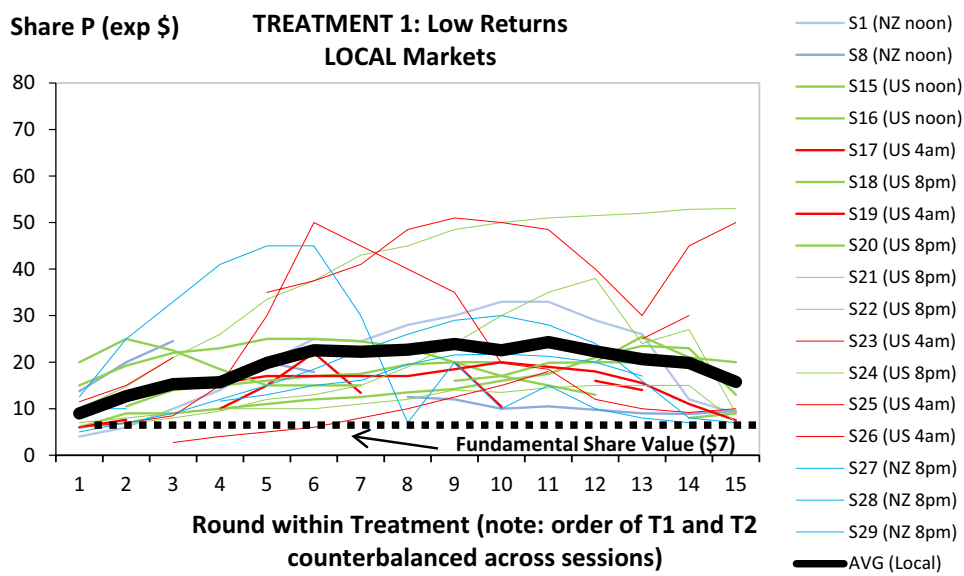

Panel B: global markets

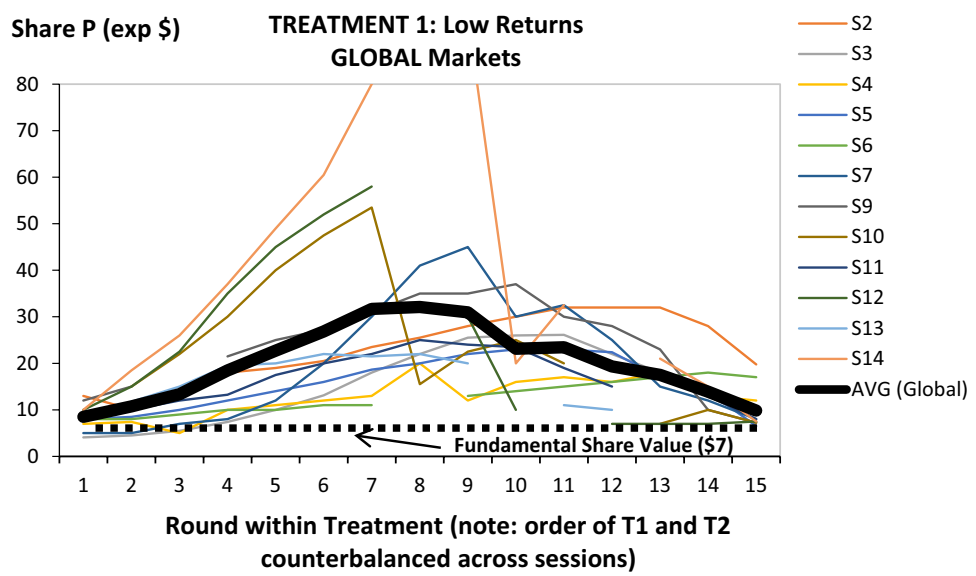

Fig. 2 Local versus global markets: prices across rounds in low returns treatment. (Color figure online) Note: A gap in the market price graph typically indicates there were no shares traded in that period of that session. However, the gaps at price levels above $\$ 80$ for some sessions in the global market data panels (both in Figs. 2 and 3) are purely an artefact of our scaling the share price axis to a maximum of $\$ 80$ for consistency and legibility 
represents the average market price across all sessions shown in the same plot. It is clear from Figs. 2 and 3 that price bubbles are the norm in all markets we ran. It is less clear as to whether there are systematic differences between global and local markets. In order to explore this further, we focus our attention on the circadian GINI measure of a market, which best captures the degree of market level heterogeneity. As shown in Table 1 above, on average, global markets exhibit significantly higher levels of circadian heterogeneity, compared to local markets.

\section{Panel A: local markets}
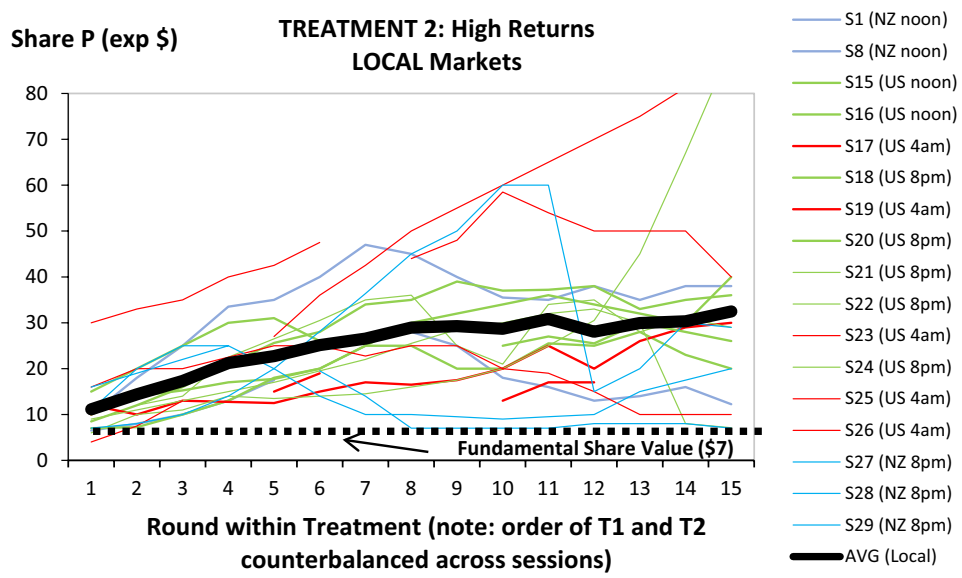

Panel B: global markets

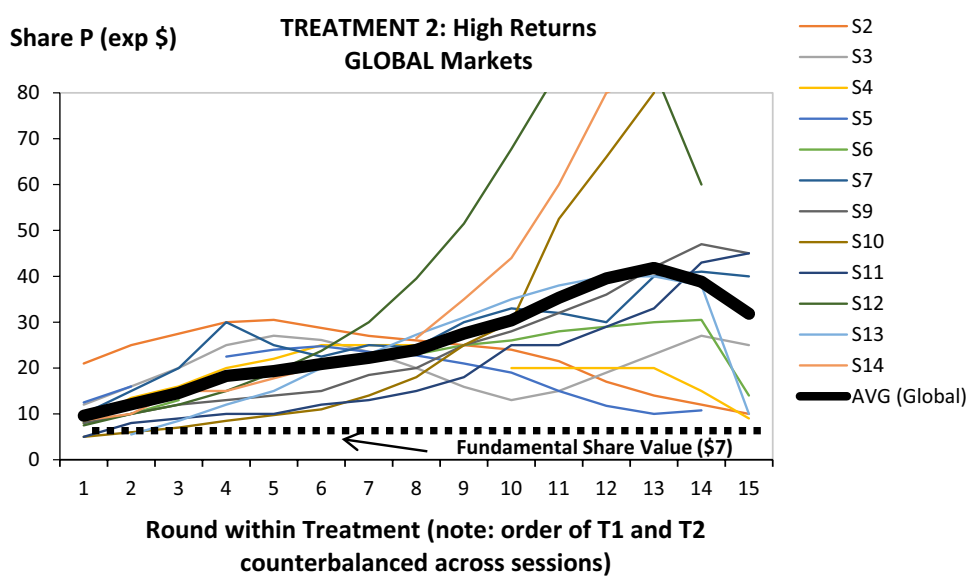

Fig. 3 Local versus global markets: prices across rounds in high returns treatment. (Color figure online) Note: Inadvertently, the High Returns treatment in Session 1 (local market) ran for 20 rounds instead of 15 . While we include the market prices for rounds $1-15$ of that session with other local market sessions, we do not include these for further data analysis. Because the High Returns treatment followed low returns in that session, the low returns treatment data for that session are unaffected and therefore have been retained 
In order to test for mispricing at the market level, we focus on whether the circadian GINI coefficient measure, as defined in Eq. (1), predicts market bubble activity. We examine the following bubble measures: (1) Maximum Price: the maximum market clearing share price in the market (across all rounds); (2) Bubble Duration: the longest run of market price increases across consecutive rounds; (3) Normalized average price deviation (NAPD): the sum of the absolute deviations of market price from fundamental share value for each trading round and (4) Turnover: transaction volume across all trading rounds relative to total available shares (see Palan 2013; Corgnet et al. 2015).

Table 2 shows results from log-log specification regressions estimating the impact of the market-level circadian GINI coefficient on the market-level bubble measure for that treatment (see Table A1 in online supplementary material for the bubble measures of each individual market). We choose to implement a log-log specification here, since that allows us to present these results as elasticities, which is an intuitive way of thinking about the relationship between the GINI coefficient and the bubble measure. It allows us to ask: what is the percentage change in a particular measure given a $1 \%$ increase in the Gini? These regressions consider the market as the independent observation, and so we are somewhat limited in the statistical power of such market-level estimations.

Results from Table 2 show a significant impact of circadian heterogeneity in the High Returns treatment on two of the bubble measures: bubble duration and turnover. Estimates indicate that a $100 \%$ increase in the circadian GINI of a market (which is not abnormal across our market-level GINI coefficients; see Table 1), is predicted to increase bubble duration by $22 \%$ (approximately 3 rounds of our 15-round treatment). A similar increase in market-level GINI predicts an increase in share turnover of $11 \%$, which is an indicator of increased market volume of trades. This latter finding is in line with the results in Michailova and Schmidt (2016), who find larger bubbles and increased trade volume in highoverconfidence markets. The fact that we estimate these effects only in the High Returns treatment imply that, at least in our laboratory environment, heterogeneity may only manifest at the market level when conditions are conducive to large valuation bubbles. We therefore describe this as limited support for Hypothesis

Table 2 Circadian GINI impact on the log asset market bubble measures ( $\mathrm{n}=28$ markets)

\begin{tabular}{|c|c|c|c|c|c|c|c|c|}
\hline \multirow[b]{2}{*}{ Variable } & \multicolumn{4}{|c|}{$\begin{array}{l}\text { Low returns } \\
\text { Coefficients (SE) }\end{array}$} & \multicolumn{4}{|c|}{$\begin{array}{l}\text { High returns } \\
\text { Coefficients (SE) }\end{array}$} \\
\hline & $\begin{array}{l}\text { Max } \\
\text { price }\end{array}$ & $\begin{array}{l}\text { Bubble } \\
\text { duration }\end{array}$ & NAPD & Turnover & $\begin{array}{l}\text { Max } \\
\text { price }\end{array}$ & $\begin{array}{l}\text { Bubble } \\
\text { duration }\end{array}$ & NAPD & Turnover \\
\hline Constant & $\begin{array}{l}3.460 * * * \\
(0.221)\end{array}$ & $\begin{array}{l}1.934 * * * \\
(0.257)\end{array}$ & $\begin{array}{l}4.926 * * * \\
(0.266)\end{array}$ & $\begin{array}{l}0.208 * * * \\
(0.168)\end{array}$ & $\begin{array}{l}3.645^{* * * *} \\
(0.249)\end{array}$ & $\begin{array}{l}2.415^{* * * *} \\
(0.261)\end{array}$ & $\begin{array}{l}5.424 * * * \\
(0.257)\end{array}$ & $\begin{array}{l}0.443 * * * \\
(0.13)\end{array}$ \\
\hline $\log ($ Gini) & $\begin{array}{l}0.022 \\
(0.084)\end{array}$ & $\begin{array}{l}0.046 \\
(0.097)\end{array}$ & $\begin{array}{l}-0.055 \\
(0.101)\end{array}$ & $\begin{array}{l}0.085 \\
(0.064)\end{array}$ & $\begin{array}{l}-0.023 \\
(0.094)\end{array}$ & $\begin{array}{l}0.22 * * * \\
(0.099)\end{array}$ & $\begin{array}{l}-0.008 \\
(0.097)\end{array}$ & $\begin{array}{l}0.110 * * * \\
(0.049)\end{array}$ \\
\hline R-squared & .0027 & .0087 & .0112 & .0640 & .0022 & .1606 & .0003 & .1620 \\
\hline
\end{tabular}

Market 1 inadvertently administered 20 rounds of High Returns and is therefore excluded from analysis $* * *, * *$ and $*$ denote significance at $1 \%, 5 \%$ and $10 \%$ respectively 
1; markets with higher circadian heterogeneity do lead to larger bubbles using at least two of our four metrics, but this is true only for the high returns treatment.

Result 2 Traders at more suboptimal times of day hold riskier asset portfolios and are more likely to engage in asset mispricing.

Hypothesis 1 and Result 1 above look at aggregate market level outcomes; whether markets with greater circadian heterogeneity exhibit larger bubbles. We now turn to an in-depth analysis of our second hypothesis above, which relates to individual trader-level decisions. Hypothesis 2 suggests that traders who are at sub-optimal times of day will behave differently than those who are operating at more optimal times. More specifically, the former ("tired" traders) will engage in greater asset mispricing and will also hold on to shares deeper into the game, a risky strategy given the inevitable market collapse.

We start by looking at average share holdings at different points in the market's 15-period life for subjects who are likely to be at a circadian suboptimal time of day as opposed to those who are not. For this we use the classification of circadian mismatch level, MMLevel, as defined above in Fig. 1 of Sect. 4. This variable combines both time-of-day and diurnal preference of each trader. For example, the most suboptimal time in our data set (e.g., anyone trading at a 4:00 am local time-of-day, as well as evening-types at 8:00 am or morning types at midnight), we consider as highly circadian mismatched, or HighMM $=1$. These are all traders with $M M L e v e l \geq 0.50$. The rest of the traders have MMlevel $<0.50$ and are classified as HighMM=0. One can see from Fig. 1 that there is a gap in MMlevel of our traders between what we score as $H i g h M M=0$ and 1. For ease of exposition, we will often refer to HighMM=1 traders as "tired" or "sleepy" and the HighMM=0 traders as "alert".

This classification approach ignores any compensatory behaviors of the subject to combat sleepiness, for which we did not collect data. While this may seem a limitation in our data, we document the validity of this approach using the common 9-point Karolinska self-reported sleepiness rating scale (or KSS, see Åkerstedt and Gillberg 1990). For the KSS, $1=$ lowest and 9=highest sleepiness rating. This information is elicited in the online survey administered immediately prior to the asset market trading experiment. Using data from all of our 29 experimental sessions $(n=303$ total subjects), we report a significantly higher self-reported sleepiness among $\operatorname{HighMM}=1$ subjects $(\mathrm{n}=81, \mathrm{KSS}=6.06 \pm 1.57)$ compared to the HighMM $=0$ subjects $(\mathrm{n}=222, \mathrm{KSS}=4.92 \pm 1.78)$ using the nonparametric Mann-Whitney two-sample test of medians $(\mathrm{z}=-4.961 ; p<0.01)$.

Our global markets are those with the most intra-market heterogeneity in circadian mismatch levels, on average, due to the different local times of day for the traders in those markets. While time-of-day describes the typical main source of circadian heterogeneity in a market, recall that traders with different diurnal preference (e.g., morning-types versus evening-types) imply that circadian heterogeneity may yet vary in a local market where all traders are at the same local time-of-day. Our primary analysis includes both global and local markets data. We first focus on share-holdings in our examination of Hypothesis 2. 
Figure 4 shows average share holdings of tired and alert subjects pooled across sessions for a given round and treatment in all markets including those with a high or low degree of circadian mismatch. Not only are shares riskier than cash in this market experiment, but shares held late into the game are riskier than at other times in the life of the market. We divide up the 15 rounds in each treatment (low or high returns) into early rounds (Rounds 1-8) and late rounds (Rounds 9-15).

The upper panels of Fig. 4 show the patterns of share-holdings across rounds for the more heterogeneous markets (those with market level GINI coefficient above the median GINI coefficient), while the lower panel shows this for the less heterogeneous half of our sample (those with GINI coefficient below the median). Visually, one can see an apparent difference in share-holdings across rounds that exists only in

\section{Panel A: high circadian Gini markets —low returns and high Returns treatments}
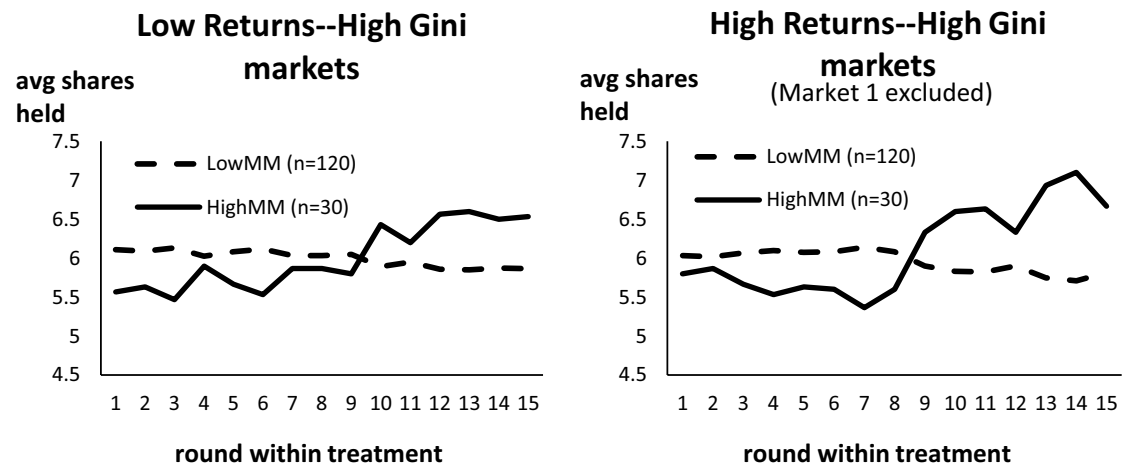

Panel B: low circadian Gini markets—low returns and high returns treatments
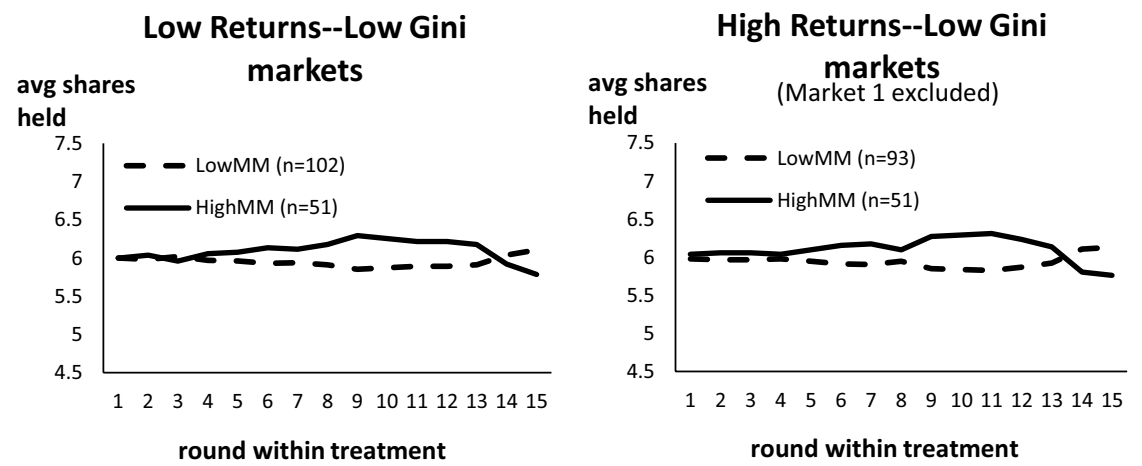

Fig. 4 Portfolio Share holdings by treatment and market Gini level

Notes: Data are pooled across all traders and markets. Data for shareholding patterns omit Market 1 from High Returns panels due to the fact that this treatment, which occurred after the Low Returns treatment in that market, was inadvertently administered for 20 rounds (instead of the usual 15). Market 1 was a Low GINI market and so exclusion of Market 1 does not reduce observations for the High GINI High Returns panel 
the more heterogeneous half. In these more heterogeneous markets, it appears that tired subjects hold more shares on average in the late rounds compared to the early rounds, which is a riskier portfolio in general (compared to cash in the experiment, which earns a certain interest rate).

It is worth highlighting again that the set of high circadian mismatch markets does not coincide exactly with the set of global markets. There are some local markets that exhibit higher circadian heterogeneity compared to some global markets (see Table 1). So, the set of high circadian mismatch markets is made up of mostly global with some local markets. Likewise, the majority of the low circadian mismatch markets are local markets, albeit not all of them.

While it may appear from panel B that HighMM=0 and HighMM=1 traders have similar share-holding patterns across rounds, keep in mind that, in the low GINI coefficient markets, the HighMM=1 traders are typically not in the same market as the HighMM $=0$ traders. In other words, panel B pools across markets and includes data from local markets at 4:00 am as well as local markets during the day (e.g., noon), both of which have low heterogeneity across traders in the markets: some markets contain all HighMM=1 traders (the 4:00 am markets) and others containing all HighMM=0 traders (the noon or 8:00 pm markets). In the High GINI markets, HighMM=0 and HighMM=1 traders are typically in the same market, which implies that the fixed numbers of shares per market may trade hands from alert to sleepy traders as seen in late round trend.

Figure 4 is therefore meant to display the apparent importance of a market's circadian heterogeneity in share-holding patterns. It appears that differences arise when circadian mismatched traders are on the presence of less circadian mismatched traders who make take advantage of these different (riskier) trading strategy preferences. We now turn to using regression analysis to provide more rigorous corroboration of some of these findings.

Table 3 presents results from random effects regressions for share-holding patterns, split into estimations using the subset of high circadian heterogeneity markets (markets with GINI coefficient greater than the median; to the left) and low circadian heterogeneity markets (markets with GINI coefficient smaller than the median; to the right). The results are presented separately for the High versus Low Returns treatments, and in each case, we present two specifications. The parsimonious specification includes the dummy variable HighMM (=1 for those with high circadian mismatch, MMLevel $>0.5$; 0 otherwise), another dummy LateRound ( $=1$ if Round > 8; 0 otherwise), an interaction term between HighMM and LateRound, and a constant. The alternative specification adds the following control variables to the ones in the first specification: Female (dummy variable; 1 for women and 0 for men), MathGood (dummy variable: MathGood=1 if subject's self-reported math level out of High School is high ${ }^{15}$; Epworth (daytime sleepiness scores; higher scores

\footnotetext{
15 The scoring of MathGood=1 accounted for differences in the average math levels of New Zealand versus U.S. students. Specifically, we asked subjects to self-report their grade in the last high school math course they took. Taking into account the different grading standards, we scored $45 \%$ of the U.S. subjects $(\mathrm{n}=85$ of 187 total US participants) as MathGood $=1$ and $55 \%$ of the New Zealand subjects $(\mathrm{n}=62$ of 116 total NZ participants) as MathGood $=1$.
} 


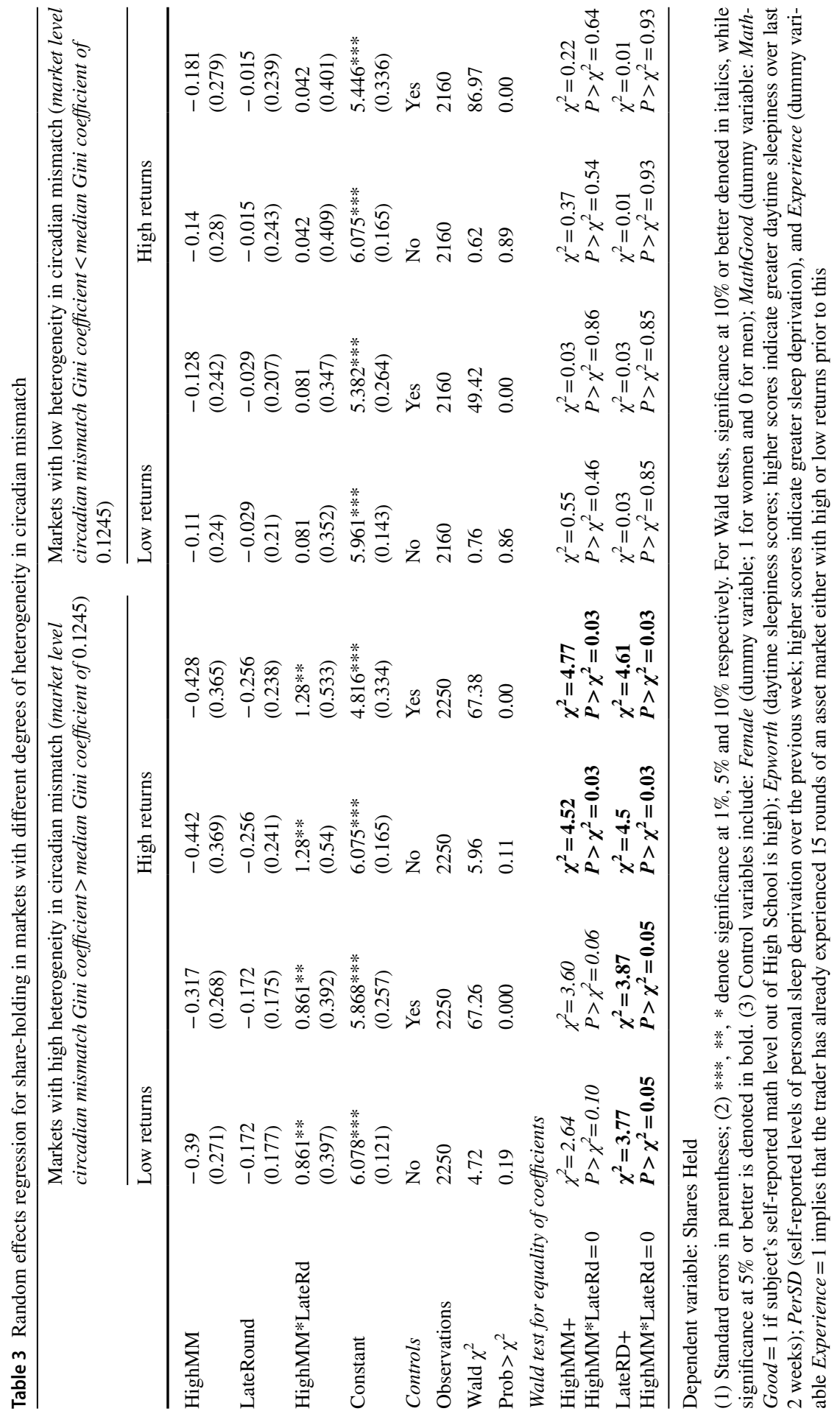


indicating greater daytime sleepiness over last 2 weeks) ${ }^{16}$; PerSD (self-reported levels of personal sleep deprivation over the previous week; higher scores indicate greater sleep deprivation), and Experience (dummy variable Experience $=1$ implies the second treatment within a particular asset market session, given that each trader experiences both a high returns and a low returns treatment). When Experience $=1$, this implies that the trader has already experienced 15 rounds of an asset market either with high or low returns and (likely) market-level mispricing prior to this. Throughout we find that our main findings do not change when controls are included in the relevant regressions.

The results in Table 3 corroborate the findings reported in Fig. 4. First, suboptimal time-of-day traders hold more shares in later rounds compared to other traders. To see this, first note that the average number of shares held late in the game by an alert trader is given by (constant+LateRound), whereas the average number of shares held late in the game by a sleepy trader is (constant +LateRound + HighMM + HighMM*LateRound). Thus if (HighMM+HighMM*LateRound $)$ is significantly greater than zero, tired subjects hold more shares than alert subjects in later rounds. In all model specifications, (HighMM+HighMM*LateRound) is positive, and the Wald test on the linear restriction (HighMM+HighMM*LateRound $)=0$ can be rejected at a 5\% level for the High Returns treatment, and marginally rejected in the Low Returns treatment (significance of the Wald test at 5\% or better is shown in bold, while significance at $10 \%$ or better is italicized).

Secondly, the suboptimal time-of-day traders increase their shareholdings between early and late rounds. To see this, first note that the average number of shares held early in the game by a sleepy trader is given by (constant + HighMM), whereas the average number of shares held late in the game by a sleepy trader is (constant+LateRound +HighMM +HighMM*LateRound). Thus, if (LateRound + HighMM*LateRound) is significantly greater than zero, tired subjects increase shareholdings on average between early and late rounds. This also supports Hypothesis 2. In all specifications, (LateRound +HighMM*LateRound) is positive, and the Wald test on the linear restriction (LateRound + HighMM $*$ LateRound $)=0$ can be rejected at a $5 \%$ level. $^{17}$

As expected, these results only manifest in markets with higher circadian heterogeneity. The estimations in Table 3, therefore, highlight that the circadian mismatch level of a trader only predicts riskier shareholdings patterns when that trader is in a market with other traders who are less circadian mismatched. We have also noted earlier that global markets, on average, tend to exhibit higher degrees of circadian heterogeneity. Therefore, we expect this tendency to hold shares deeper into the

\footnotetext{
16 The Epworth Sleepiness Scale (Johns 1991) is often used in sleep studies.

17 Unfortunately, we did not elicit beliefs from traders regarding expected dividend outcomes or asset prices, which would have helped to discriminate between the different potential mechanisms that could all contribute to tired subjects holding more shares in later rounds. For example, though tired subjects are predicted to be both more overconfident in holding shares and also less able to anticipate a market downturn, our data may not be sufficient to distinguish between these two mechanisms. However, earnings analysis we conduct later in this section may help identify whether risk taking plays an important role independent of anticipation and overconfidence.
} 
game to also manifest itself more in global markets. We present results separately for global and local markets in supplementary online material (Table A2). This table corroborates the results from Table 3; i.e., in global markets, tired traders hold more shares in later rounds. ${ }^{18}$

In Table 4, we report results of random effects regressions for individual share mispricing, which measures the extent to which the individual's trading behavior contributes to mispricing of the asset in the market. Here, we hypothesized that mispricing in asset markets will likely result from our underlying behavioral hypotheses of how circadian suboptimal timing will impact portfolio choices. We define Mispricing as:

$$
\text { QBid }_{t} *\left(\text { BidPrice }_{t}-\text { Price }_{t-1}\right)+\text { QAsk }_{t} *\left(\text { AskPrice }_{t}-\text { Price }_{t-1}\right)
$$

The intuition behind Mispricing is to construct a variable that would allow us to examine whether sleepy or alert traders were more responsible for pushing prices up. Note that this version of mispricing is taken to be relative to the previous round price rather than fundamental share value of $\$ 7$, and is weighted by the number of shares demanded/offered. Market prices almost always trade above fundamental value in our markets, and this bias measure will better capture bid/ask behavior that feeds or deflates the market level mispricing. Specifically, positive values of mispricing are pushing the bubble higher, while negative values bring it back towards the fundamental value. The use of both bid and ask prices in our mispricing measure is appropriate given that the Veconlab software call auction rules dictate market prices at the midpoint of the bid-ask spread for mutually beneficial trades-thus, both bid and ask prices can bid up market prices in our environment.

We undertake the same comparisons in Table 4 as in Table 3. ${ }^{19}$ First, we find evidence in the High Returns treatments that circadian mismatched traders misprice share more than do the more alert traders in later trading rounds in both the high and low circadian heterogeneity markets (tests of HighMM + HighMM*LateRd=0). The estimated effect size is, however, much larger in the highly heterogeneous markets compared to the low heterogeneity markets. This share mispricing result is also found in the Low Returns treatment in the low circadian heterogeneity markets, although the effect is less precisely estimated and smaller in magnitude.

Secondly, we find that tired traders increase their own bid and offer prices as the game progresses in the High Returns treatment in high circadian heterogeneity

\footnotetext{
18 As noted earlier, we also replicate all our results replacing the HighMM dummy with the underlying continuous variable MMLevel $\in[0,1]$. These results are similar to those in Table 3, except that for markets with heterogeneity above the median, we get significant differences in the High Returns treatment when using HighMM in Table 3 but we do not get significant differences in the High Returns treatment when we use MMLevel. We still get similar significant differences in the Low Returns treatment. As in Table 3 we do not find any significant differences in the markets below the median if we use MMLevel. In the interest of parsimony, we do not present these results in detail, but they are available from the corresponding author upon request.

19 Reduced observations in the Table 4 regressions (compared to Table 3) are due both to the use of lagged terms in constructing the mispricing measures and the fact that some rounds did not produce a market price observation if no shares were traded.
} 


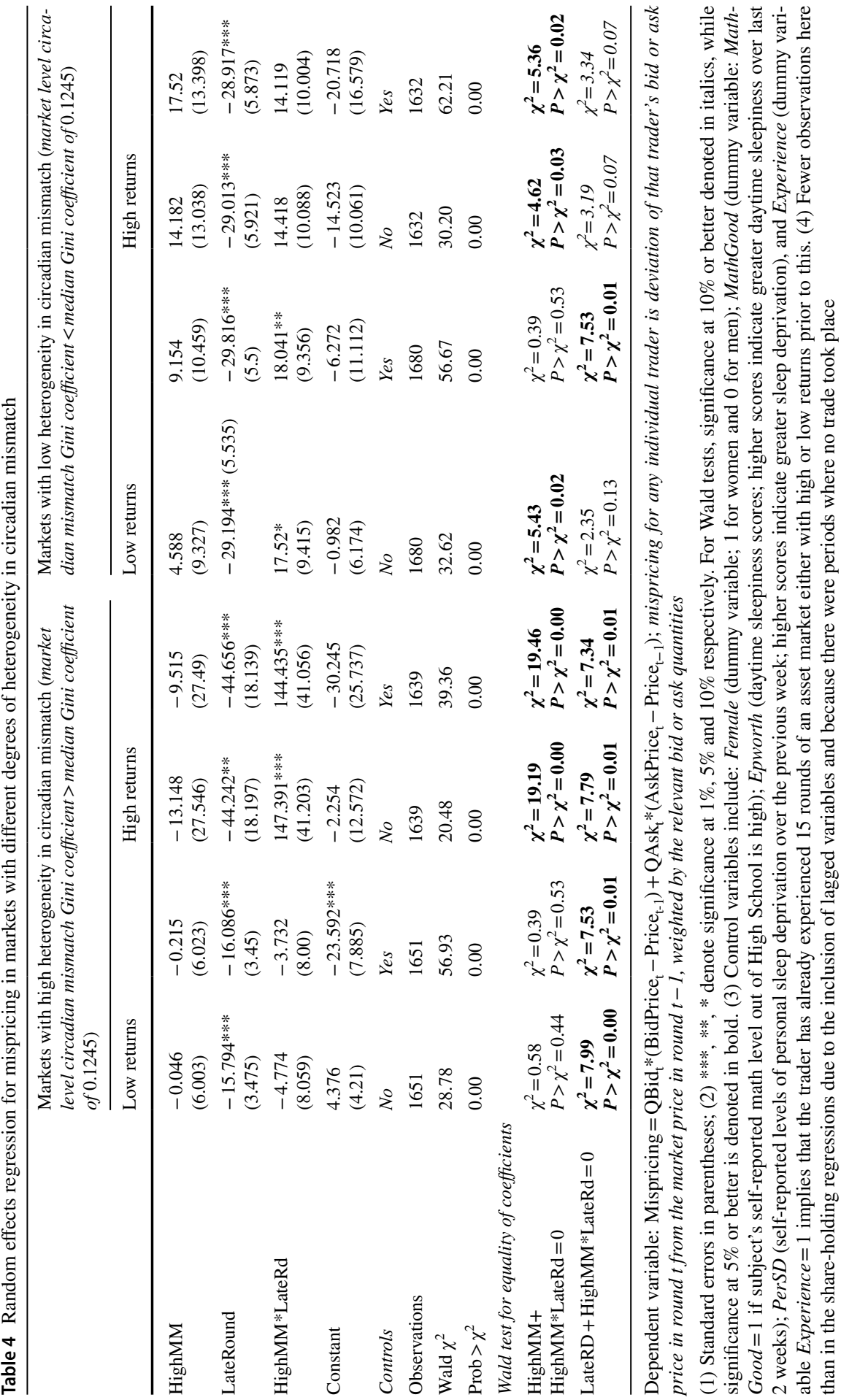


markets (test of LateRound + HighMM*LateRd $=0$ ). The general trend among alert traders is to misprice to a lesser extent in late rounds of trading (LateRound coefficient uniformly negative and significant in all specifications), but at least in some instances sleepy traders display the opposite tendency. This is most notable in the significant increase in mispricing in the High Returns treatment of high circadian heterogeneity market. In that case, the circadian mismatched traders reverse their own tendency to decreasingly misprice shares with each passing round, which is the general tendency of all traders. In sum, our Table 4 results show varied evidence regarding whether circadian mismatched traders exhibit increased mispricing tendencies in later rounds compared to themselves in the early rounds, but we find consistent evidence that in the High Returns treatments sleepy traders misprice in late rounds more than alert traders in late rounds (Hypothesis 2). The general findings in Tables 3 and 4 are limited to High Returns treatments, which is consistent with the market level bubble impacts in Table 2 also being confined to the High Returns treatment.

As in the case of Table 3, supplementary online material (Table A3) contains results for mispricing from global and local markets. The results are similar. Global markets, which are typically more heterogeneous, show evidence of circadian mismatched traders driving mispricing, except there is some evidence of tired traders mispricing in local markets as well. We also undertook a robustness test using MMLevel instead of HighMM and the results are very similar to that presented in Table 4 (available on request).

Result 3 Circadian mismatched traders earn less. This effect is significant and strongest in markets with the highest circadian GINI coefficients (i.e., the most circadian heterogeneous markets).

Our third and final hypothesis is that traders operating at sub-optimal times of the day will earn less. In Table 5, we present random effects regressions for log final earnings, i.e., cumulative earnings for each trader at the very end of the session. Once again, the regressor of primary interest is HighMM, the dummy which takes the value of 1 for traders at sub-optimal times of day (tired) traders. If our hypothesis is correct, then we expect a negative and significant coefficient for this dummy, indicating that tired traders earn less in the experiment. We present three different sets of results for markets where the Circadian GINI (the market level measure of heterogeneity in mismatch) is (1) above the median; (2) in the topthird (top tercile) and (3) in the top quartile. In each case we present results separately for Low Returns and High Returns treatments. For each treatment, we present results for two regression specifications: a parsimonious specification which includes only the HighMM dummy and a constant and a second full model which includes other control variables. The controls in Table 5 are the same as those in Tables 3 and 4 (and are also explained beneath the table). Analogous results for markets with Circadian GINI below the median, in the lower tercile and the lower quartile as well as for global and local markets is available in the online supplementary materials (Tables A4 and A5, respectively). 


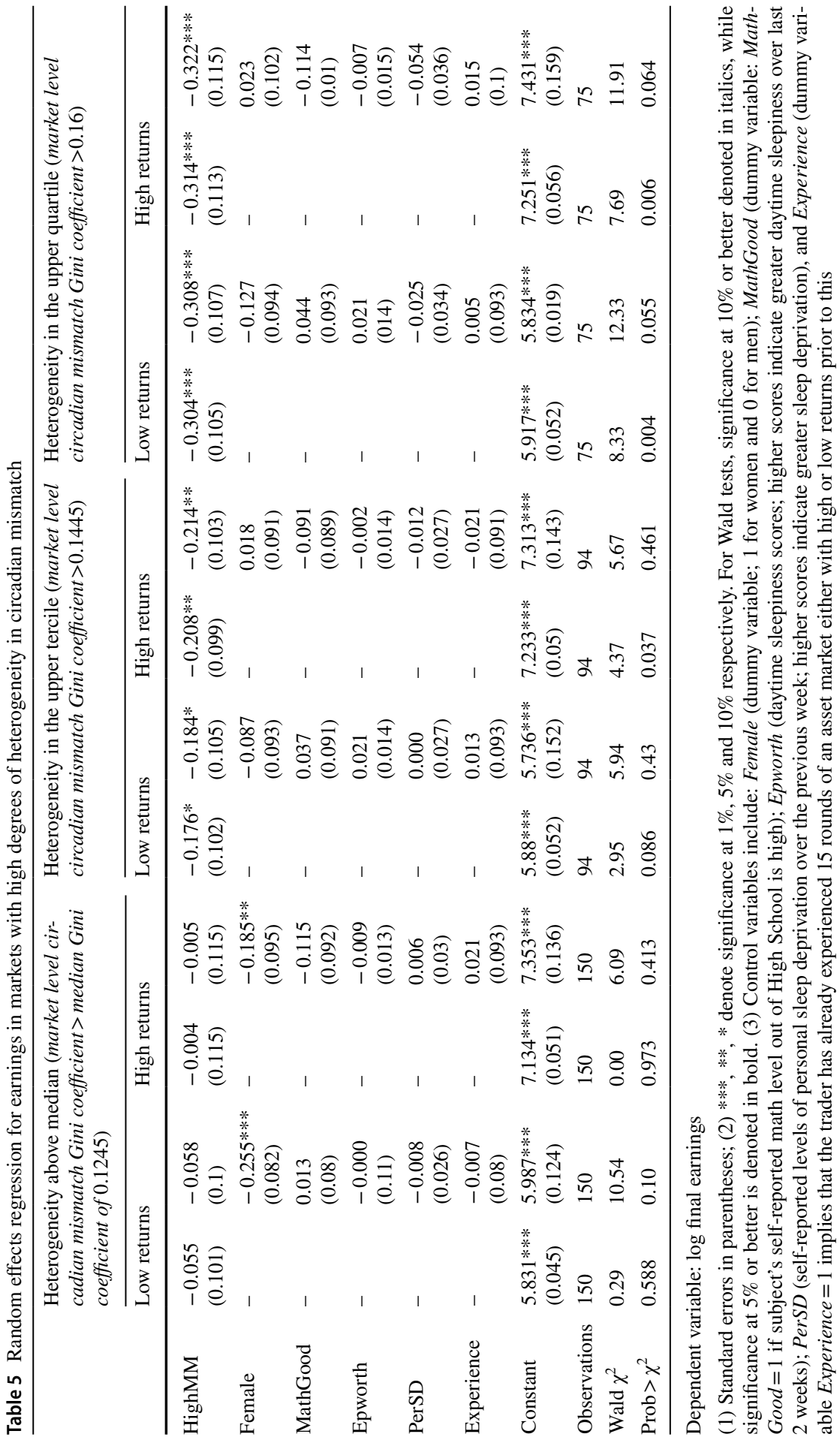


The evidence presented in Table 5 shows that tired traders earn less, and this result is particularly pronounced for markets with relatively high degree of circadian mismatch; i.e., markets with circadian GINI in top tercile or top quartile. First, we look at market with Circadian GINI above the median. Here, while the sign of the HighMM dummy is always negative, none of these rises to conventional levels of significance. But from that point on, as we move to markets with greater heterogeneity, i.e., those in the top third or top quarter for the GINI coefficient for circadian mismatch, the coefficient for the HighMM dummy becomes negative and significant. If we look only at the markets in the top quarter, i.e., those markets with circiadian GINI greater than 0.16 , then, on average, tired traders may be earning approximately a third less than alert traders, which is consistent with Hypothesis 3.

In supplementary online material (Table A4), we present earnings results for markets with limited heterogeneity in circadian mismatch. These are markets, whose circadian GINI are located (1) below the median; (2) in the bottom tercile and (3) in the bottom quartile. It is clear that we do not see any evidence of earnings differentials between tired and alert traders in these markets. This is most likely because traders in these markets are at similar levels of circadian mismatch and therefore, there are no alert traders to take advantage of the cognitive deficiencies of the sleepier traders.

In supplementary online material (Table A5), we present the results for earnings broken up by local and global markets. However, final earnings are not significantly different between local and global markets. So, while earnings for tired traders are significantly lower than those for alert traders in markets with a higher degree of circadian heterogeneity, we do not find these differences mirrored in global markets. This somewhat qualifies our evidence in support of Hypothesis 3, and can be due to at least a couple of reasons. First, recall that not all global markets have higher-thanmedian circadian mismatch across our market sessions. Focusing on markets in the top tercile and quartile of circadian heterogeneity eliminates local markets as well as the not-so-heterogeneous global markets. Second, it is possible that the flat fundamental share-value design we have implemented masks some earnings differences that would more readily appear in a declining fundamental value paradigm. ${ }^{20}$

\section{Conclusion}

We explore an under-appreciated characteristic of global financial markets in the sense that some traders engaged in these markets are making decisions at suboptimal times of day. This implies variations in the circadian timing of decisions, which may be an important heterogeneity in the cognition of traders that is present

\footnotetext{
20 The earnings regressions we report contain data for 294 participants rather that 303 . This is because, as noted in Table 3 above, the very first session, a local session with 9 participants had 20 rounds in the High Returns treatment as opposed to the required 15. We have taken out this session in looking at final earnings resulting in dropping 9 participants, thereby reducing the number of observations from 303 to 294.
} 
particularly in global markets. At the aggregate level, we found that this heterogeneity in circadian mismatch of traders predicts, at least, some aggregate marketlevel measures of mispricing, such as longer duration of asset price bubbles or greater turnover volume. This is particularly true in a higher cash (greater liquidity) environment (High Returns) that tends to produce larger bubbles in general. At the individual trader level, we found that, when market mismatch heterogeneity is high, those trading at sub-optimal times-of-day tended to engage in different trading behaviors than those trading at more favorable times. The tired traders tended to hold shares (the risky asset) deeper into the market trading rounds. They also exhibit a greater degree of mispricing of shares, in the sense that their bid and ask prices in any round were further above the market price in the previous round. These effects are most robust in the High Returns treatment and in markets that display more circadian heterogeneity across traders. We also find evidence that these tired traders earn less, especially in markets that have the most circadian heterogeneity. This implies that tired trader strategies are suboptimal and can be effectively exploited by more alert traders in a way that directly impacts trader earnings and potentially market level outcomes. As noted before, these differences between trader types arise when circadian mismatched traders are in the presence of less circadian mismatched traders who can effectively exploit riskier trading strategies.

We note several distinct behavioral mechanisms that may point to similar predictions regarding trader behavior. Though our data are not sufficient to provide direct evidence for testing between different mechanisms, the data are more consistent with a mechanism of decreased anticipation and/or increased overconfidence generating the shareholding patterns we observe. Results in Lei et al. (2001) suggest irrationality of traders may drive speculative bubbles and, to some, our data may suggest irrationality among tired traders. Yet, the relatively mild sleepiness generated in our protocol has been previously shown to impact the riskiness in chosen asset bundles in an individual choice task (Castillo et al. 2017). Riskier portfolio choice in the present experiment does not, however, explain late-round share purchases at inflated prices when history has shown little chance of resale for capital gain. This feature of our data is more consistent with a mechanism of decreased anticipation (theory of mind) and/or increased overconfidence among sleepier traders to generate the observed patterns in shareholdings and mispricing.

Others have theoretically argued that the failure of rational arbitrageurs to coordinate selling activity may also cause bubbles to persist (Abreu and Brunnermeier 2003). This may imply yet another mechanism to explore in light of other recent findings that suggest sleepiness may increase the likelihood of coordination failure (Castillo and Dickinson 2018). Recent results showing intra-day trading patterns that could be due to heterogeneity in trader information processing (Gao et al. 2018) may also be consistent with heterogeneity in trader sleepiness. A different experimental design may be required of future research in order to more directly examine the cognitive underpinnings of sleepy trader decisions and assess which components are most impacted when sleepy in order to answer some of these deeper questions.

To what extent are these results generalizable to real life global asset markets? Is it not the case that in actual markets those trading at sub-optimal times are 
self-selected and, therefore, better able to handle any potential circadian mismatch? We believe that these concerns are unfounded. For one thing, even among our subjects there was a degree of self-selection; subjects were free to choose their session time-slots and it is likely that the ones who thought they could handle the adverse time-of-day sessions were more likely to select into those sessions. This actually implies our results would be a conservative estimate of the true impact of suboptimal times-of-day on trading decisions (i.e., the traders at the most suboptimal timesof-day would be those who felt they could handle it best). The point here is that a measure of self-selection in our experimental subjects somewhat mimics a feature of naturally occurring field data on trader behavior.

But more fundamentally we are making two points. First, the presence of circadian mismatch and heterogeneity in local times-of-day across traders is a feature that looms larger for global markets than for local markets. This may lead to differences in market-level outcomes. Second, those operating at sub-optimal times of day will engage in differential trading strategies that may involve riskier portfolio choices or behaviors otherwise symptomatic of cognitive impairment. In the presence of other more alert traders, these sleepy traders may be exploited and experience a negative impact on earnings. It is our hope that the effects of circadian state, and how markets with greater circadian heterogeneity may magnify trading behavior differences, will stimulate further interest in examining different types of cognitive heterogeneity in asset markets.

Acknowledgements The authors thank the Walker College of Business and the University Research Council at Appalachian State University, as well as the University of Auckland Faculty Research Development Fund for funding this research. Valuable research assistance was provided by Ananrita Chaudhuri, James Jones, Sherry Li, Ryan Mills and Tony So. We are grateful to Brice Corgnet and Henk Berkman for providing valuable comments on multiple occasions. We have benefited greatly from feedback provided by participants in many conferences including those at the Economic Science Association Annual Meetings (San Diego, CA), Economic Science Association North American Meetings (Tucson, AZ and Richmond, VA), Economic Growth and Development Conference (New Delhi, India) as well as seminar participants at Monash University, Middlesex University, Utah State University, and Appalachian State University. We sincerely appreciate the feedback provided by Charles Noussair, the editor in charge of handing the paper, as well as two anonymous reviewers.

\section{References}

Abreu, D., \& Brunnermeier, M. K. (2003). Bubbles and crashes. Econometrica, 71(1), 173-204.

Adan, A., \& Almirall, H. (1991). Horne \& Östberg morningness-eveningness questionnaire: A reduced scale. Personality and Individual Differences, 12(3), 241-253.

Åkerstedt, T., \& Gillberg, M. (1990). Subjective and objective sleepiness in the active individual. International Journal of Neuroscience, 52(1-2), 29-37.

Akiyama, E., Hanaki, N., \& Ishikawa, R. (2017). It is not just confusion! Strategic uncertainty in an experimental asset market. Economic Journal, 127(605), F563-F580.

Baghestanian, S., Lugovskyy, V., \& Puzzello, D. (2015). Traders' heterogeneity and bubble-crash patterns in experimental asset markets. Journal of Economic Behavior \& Organization, 117, 82-101.

Bostian A. J., Goeree, J., \& Holt, C. A. (2005). Price bubbles in asset market experiments with a flat fundamental value. In Draft for the experimental finance conference. Federal Reserve Bank of Atlanta, 23 September 2005.

Bostian, A. J., \& Holt, C. A. (2009). Price bubbles with discounting: A web-based classroom experiment. The Journal of Economic Education, 40(1), 27-37. 
Bruguier, A. J., Quartz, S. R., \& Bossaerts, P. (2010). Exploring the nature of 'trader intuition'. Journal of Finance, 65(5), 1703-1723.

Castillo, M., \& Dickinson, D. L. (2018). Sleep restriction increases coordination failure. Working paper.

Castillo, M., Dickinson, D. L., \& Petrie, R. (2017). Sleepiness, choice consistency, and risk preferences. Theory and Decision, 82(1), 41-73.

Chee, M. W., \& Chuah, L. Y. (2008). Functional neuroimaging insights into how sleep and sleep deprivation affect memory and cognition. Current Opinion in Neurology, 21(4), 417-423.

Chen, K. C., Li, G., \& Wu, L. (2010). Price discovery for segmented US-listed Chinese stocks: Location or market quality? Journal of Business Finance \& Accounting, 37(1-2), 242-269.

Corgnet, B., DeSantis, M., \& Porter, D. (2018). What makes a good trader? On the role of reflection and intuition on trader performance. Journal of Finance., 73, 1113-1137.

Corgnet, B., Hernán-González, R., Kujal, P., \& Porter, D. (2015). The effect of earned versus house money on price bubble formation in experimental asset markets. Review of Finance, 19(4), 1455-1488.

Coricelli, G., \& Nagel, R. (2009). Neural correlates of depth of strategic reasoning in medial prefrontal cortex. Proceedings of the National Academy of Sciences, 106(23), 9163-9168.

De Long, J. B., Shleifer, A., Summers, L. H., \& Waldmann, R. J. (1990). Positive feedback investment strategies and destabilizing rational speculation. The Journal of Finance, 45(2), 379-395.

Dickinson, D. L., \& Drummond, S. P. A. (2008). The effects of total sleep deprivation on Bayesian updating. Judgment and Decision Making, 3(2), 181-190.

Dickinson, D. L., Drummond, S. P. A., \& Dyche, J. (2016). Voluntary sleep choice and its effects on Bayesian decisions. Behavioral Sleep Medicine, 14(5), 501-513.

Dickinson, D. L., \& McElroy, T. (2012). Circadian effects on strategic reasoning. Experimental Economics, 15(3), 444-459.

Frederick, S. (2005). Cognitive reflection and decision making. Journal of Economic Perspectives, 19(4), 25-42.

Gao, L., Han, Y., Li, S. Z., \& Zhou, G. (2018). Market intraday momentum. Journal of Financial Economics. https://doi.org/10.1016/j.jfineco.2018.05.009.

Griffin, J. M., Harris, J. H., Shu, T., \& Topaloglu, S. (2011). Who drove and burst the tech bubble? The Journal of Finance, 66(4), 1251-1290.

Grinblatt, M., \& Keloharju, M. (2009). Sensation seeking, overconfidence, and trading activity. Journal of Finance, 64(2), 549-578.

Hampton, A. N., Bossaerts, P., \& O’Doherty, J. P. (2008). Neural correlates of mentalizing-related computations during strategic interactions in humans. Proceedings of the National Academy of Sciences, 105(18), 6741-6746.

Hanaki, N., Akiyama, E., Funaki, Y., \& Ishikawa, R. (2017). Diversity in cognitive ability enlarges mispricing in experimental asset markets. GREDEG working paper no. 2017-08.

He, H., \& Yang, J. (2012). Day and night returns of Chinese ADRs. Journal of Banking \& Finance, 36(10), 2795-2803.

Hefti, A., Heinke, S., \& Schneider, F. (2016). Mental capabilities, trading styles, and asset market bubbles: Theory and experiment. Working paper. University of Zurich, Department Economics \#234.

Hirshleifer, D., \& Shumway, T. (2003). Good day sunshine: Stock returns and the weather. Journal of Finance, 58(3), 1009-1032.

Holt, C. A., Porzio, M., \& Song, M. Y. (2017). Price bubbles, gender, and expectations in experimental asset markets. European Economic Review, 100, 72-94.

Horne, J. A. (1993). Human sleep, sleep loss and behavior. Implications for the prefrontal cortex and psychiatric behavior. British Journal of Psychiatry, 162, 413-419.

Johns, M. W. (1991). A new method for measuring daytime sleepiness: The Epworth sleepiness scale. Sleep, 14(6), 540-545.

Kamstra, M. A., Kramer, L. A., \& Levi, M. D. (2000). Losing sleep at the market: The daylight saving anomaly. American Economic Review, 90(4), 1005-1011.

Kirchler, E., \& Maciejovsky, B. (2002). Simultaneous over- and underconfidence: Evidence from experimental asset markets. Journal of Risk and Uncertainty, 25(1), 65-85.

Lei, V., Noussair, C. N., \& Plott, C. R. (2001). Nonspeculative bubbles in experimental asset markets: Lack of common knowledge of rationality vs. actual irrationality. Econometrica, 69(1), 831-859.

Liu, L. (2017). Return \& volatility disparity, slow adjustment process in Chinese triple-listed firms. GSTF Journal on Business Review (GBR), 2(2), 233-238. 
Michailova, J., \& Schmidt, U. (2016). Overconfidence and bubbles in experimental asset markets. Journal of Behavioral Finance, 17(3), 280-292.

Muzur, A., Pace-Schott, E. F., \& Hobson, J. A. (2002). The prefrontal cortex in sleep. Trends in Cognitive Sciences, 6(11), 475-481.

Palan, S. (2013). A review of bubbles and crashes in experimental asset markets. Journal of Economic Surveys, 27(3), 570-588.

Scheinkman, J. A., \& Xiong, W. (2003). Overconfidence and speculative bubbles. Journal of Political Economy, 111(6), 1183-1220.

Smith, C. S., Folkard, S., Schmnieder, R. A., Parra, L. F., Spelten, E., Almiral, H., et al. (2002). Investigation of morning-evening orientation in six countries using the preferences scale. Personality and Individual Differences, 32(6), 949-968.

Toplak, M. E., West, R. F., \& Stanovich, K. E. (2011). The cognitive reflection test as a predictor of performance on heuristics-and-biases tasks. Memory and Cognition, 39(7), 1275.

Venkatraman, V. L., Chuah, Y. M., Huettel, S. A., \& Chee, M. W. (2007). Sleep deprivation elevates expectation of gains and attenuates response to losses following risky decisions. Sleep, 30, 603-609.

Venkatraman, V. L., Huettel, S. A., Chuah, Y. M., Payne, J. W., \& Chee, M. W. (2011). Sleep deprivation biases the neural mechanisms underlying economic preferences. The Journal of Neuroscience, 31(10), 3712-3718.

Venkatraman, V. L., Payne, J. W., Bettman, J. R., Luce, M. F., \& Huettel, S. A. (2009). Separate neural mechanisms underlie choices and strategic preferences in risky decision making. Neuron, 62(4), 593-602.

Wu, C., \& Chen, K. (2015). Return transmissions between ADRs and A-shares of dual listed Chinese firms. Managerial Finance, 41(5), 465-479.

Yoo, S. S., Gujar, N., Hu, P., Jolesz, F. A., \& Walker, M. P. (2007). The human emotional brain without sleep-A prefrontal amygdala disconnect. Current Biology, 17(20), R877-R878.

Publisher's Note Springer Nature remains neutral with regard to jurisdictional claims in published maps and institutional affiliations.

\section{Affiliations}

\section{David L. Dickinson ${ }^{1,4,5} \cdot$ Ananish Chaudhuri ${ }^{2,3} \cdot$ Ryan Greenaway-McGrevy ${ }^{2}$}

Ananish Chaudhuri

a.chaudhuri@auckland.ac.nz

Ryan Greenaway-McGrevy

r.mcgrevy@auckland.ac.nz

1 Appalachian State University, 3090 Peacock Hall, Boone, NC 28608-2037, USA

2 University of Auckland, Auckland, New Zealand

3 CESifo, Munich, Germany

4 IZA, Bonn, Germany

5 ESI, Orange, CA, USA 